\title{
The causes and consequences of seasonal variation in COPD exacerbations
}

This article was published in the following Dove Press journal:

International Journal of COPD

6 October 2014

Number of times this article has been viewed

\section{Gavin C Donaldson Jadwiga A Wedzicha}

Airways Disease Section, National Heart and Lung Institute, Imperial College London, London, UK
Correspondence: Gavin C Donaldson Airways Disease Section, National Heart and Lung Institute, Imperial College London, Emmanuel Kaye Building, IB Manresa Road, London SW3 6LR, UK Tel +44 2075947947

Email gavin.donaldson@imperial.ac.uk
Abstract: The time of year when patients experience exacerbations of chronic obstructive pulmonary disease is a much-overlooked feature of the disease. The higher incidence of exacerbations in winter has important consequences for patients in terms of increased morbidity and mortality. The seasonality also imposes a considerable burden on already-overloaded health care services, with both primary care consultations and hospital admissions increasing in number. The seasonality of exacerbations varies with latitude, and is greater in more temperate climates, where there may be less protection from outdoor and indoor cold exposure. The precise causes of the seasonality are unknown, but thought to be partly due to the increased prevalence of respiratory viral infections circulating in cold, damp conditions. Increased susceptibility to viral infection may also be a mechanism mediated through increased airway inflammation or possibly reduced vitamin D levels. The seasonality of exacerbations informs us about the triggers of exacerbations and suggests possible strategies to reduce their number.

Keywords: exacerbations of COPD, seasonality, winter mortality, winter morbidity

\section{Definition of COPD exacerbation}

There is no simple definition of chronic obstructive pulmonary disease (COPD) exacerbation, due to the heterogeneity of causative microorganisms and environmental agents, the variety of respiratory symptoms involved, the behavior of patients with regard to seeking medical care, and the multiplicity of airway and systemic inflammatory changes. Patients typically experience acute or progressive worsening ${ }^{1}$ of one or more respiratory symptoms, particularly dyspnea, sputum purulence, and sputum volume. They may also complain of symptoms of nasal discharge, wheeze, sore throat, coughing, and/or fever. ${ }^{2,3}$ Other manifestations can include fatigue, acute confusion, malaise, or worsening exercise tolerance. ${ }^{4}$ Airway and systemic inflammatory markers increase at exacerbation, though possibly not with sufficient sensitivity and specificity for one alone to act as a biomarker of an exacerbation..$^{5-7}$ The intensity of these respiratory symptoms may cause some patients to self-treat or seek treatment from a physician. Treatment is typically with a course of antibiotics and/or oral corticosteroids. Some patients may be admitted to hospital. The decision to admit may depend on the frailty of the patient, the severity of the COPD, whether the patient is in acute respiratory failure, and the presence or not of comorbidities. Any decision to admit may also be influenced by the patient's ability to cope at home, ${ }^{8}$ the speed of access to primary care, ${ }^{9}$ and on local custom and practice, as some countries are more likely to admit a COPD patient than others. ${ }^{10}$ In elderly COPD patients, an exacerbation might result in death. This complexity in exacerbation presentation has resulted in many different 
outcomes measures being used to assess the seasonality of COPD exacerbations.

\section{Exacerbation seasonality}

So far, there has been only one global study of exacerbation seasonality. It used data collected during the 3-year TORCH (TOwards a Revolution in COPD Health) study, which was designed to investigate the components and combination of salmeterol and fluticasone propionate versus placebo and involved 6,112 patients across the globe. ${ }^{11}$ Patients were 40-80 years old with a spirometrically confirmed diagnosis of COPD and a 10 pack-year smoking history. Exacerbations were defined as events requiring treatment with antibiotics and/or oral corticosteroids, or requiring hospitalization. The analysis of seasonality was limited to data collected between April 2001 and March 2005. Figure 1 shows that the seasonal pattern of exacerbations in the northern hemisphere ( $n=4,849$ patients) mirrored that in the southern hemisphere $(n=622)$, but not in the tropics $(n=641)$. In the north, $9 \%$ of patients had exacerbations between December and February compared to $5 \%$ in June to August. This translates into an $80 \%$ winter excess in exacerbations, whereas in the southern hemisphere, $12 \%$ of patients had exacerbations in their winter (June-August) compared to $7 \%$ in summer (December-February): a 71\% winter excess. Therefore, apart from the tropics, exacerbation seasonality appears to be a global phenomenon.

Another, large multicenter investigation of seasonality used data from another randomized, controlled trial: the POET-COPD (Prevention Of Exacerbations with Tiotropium in COPD) study. ${ }^{12}$ It involved a 12-month-long follow-up of 7,376 patients living in the northern hemisphere. Exacerbations were defined as an increase in respiratory symptoms (dyspnea, cough, sputum, wheeze, or chest tightness) for 3 or more days that required treatment with oral corticosteroids and/or antibiotics or required hospitalization and were separated by at least 7 days. The study was performed between February 2008 and April 2010. Mean monthly exacerbation rates during winter (December-February) were 7.63 per 100 patient-months compared to 3.53 per 100 patient-months in summer (June-August): a 116\% winter excess.

Single-center studies have made similar observations, albeit in smaller numbers. ${ }^{13}$ In the UK, between 1995 and 2009, 307 COPD patients enrolled in a London COPD cohort recording worsening of respiratory symptoms with a paper diary to identify exacerbations using a symptomatic definition involving 2 consecutive days of one major respiratory symptom (increased dyspnea, sputum purulence, or sputum volume) plus another respiratory symptom that could be another major symptom or a minor symptom (coryzal, wheeze, sore throat, or cough). The patients experienced 1,052 exacerbations in the cold season (November-February) compared to 676 in the warm season (May-August): an excess of $56.6 \% .{ }^{14}$ Figure 2 shows that in this cohort of patients, the percentage of patients reporting respiratory symptoms or the exacerbation of an onset increased as temperatures fall, while outdoor activity and peak expiratory flow rates decrease.

In Canada, a cohort of 71 COPD patients were asked to fax daily diary sheets to a coordinating center. The center identified exacerbations when symptom levels exceeded normal for 2 consecutive days and patients were scheduled a home visit by a nurse. The study detected 47 (6.7 per week) exacerbations during the Christmas period of (December 1 to January 17) compared to 63 exacerbations (4.3 per week) during January

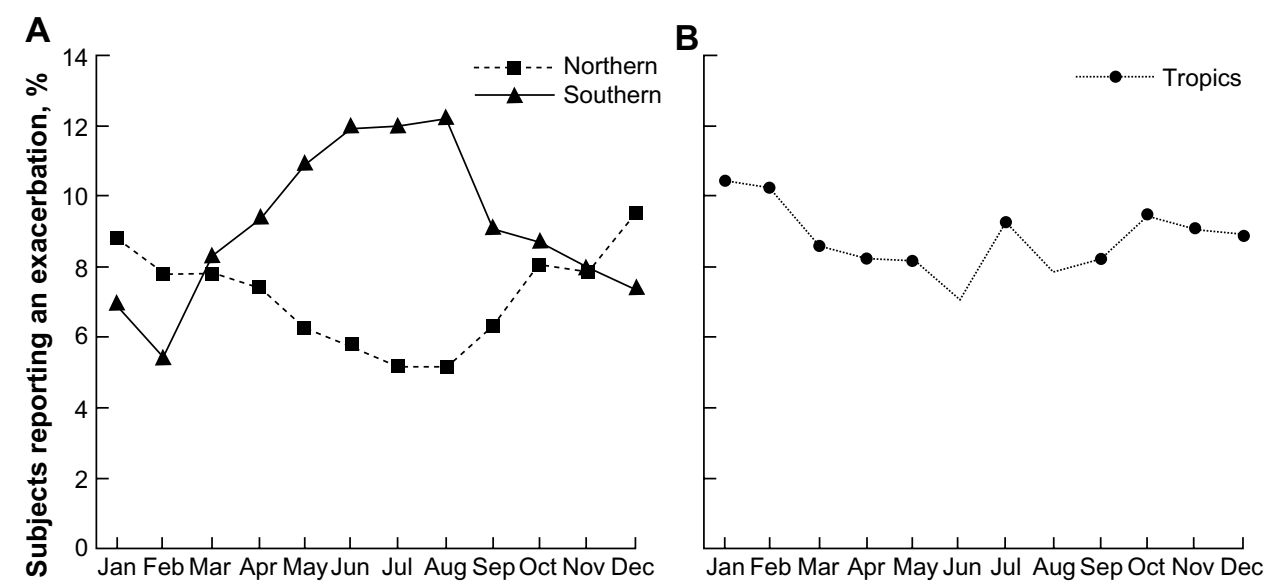

Figure I Proportion of patients reporting an exacerbation in the (A) northern or southern regions, and in (B) the tropics, averaged over I calendar year. Notes: Reproduced with permission of the European Respiratory Society. Eur RespirJJanuary 20 I 2;39:38-45; published ahead of print July 7, 20 I I, doi: I 0. I I 83/0903 I 936.00 I 946 I 0 (c) European Respiratory Society. ${ }^{\prime \prime}$ 

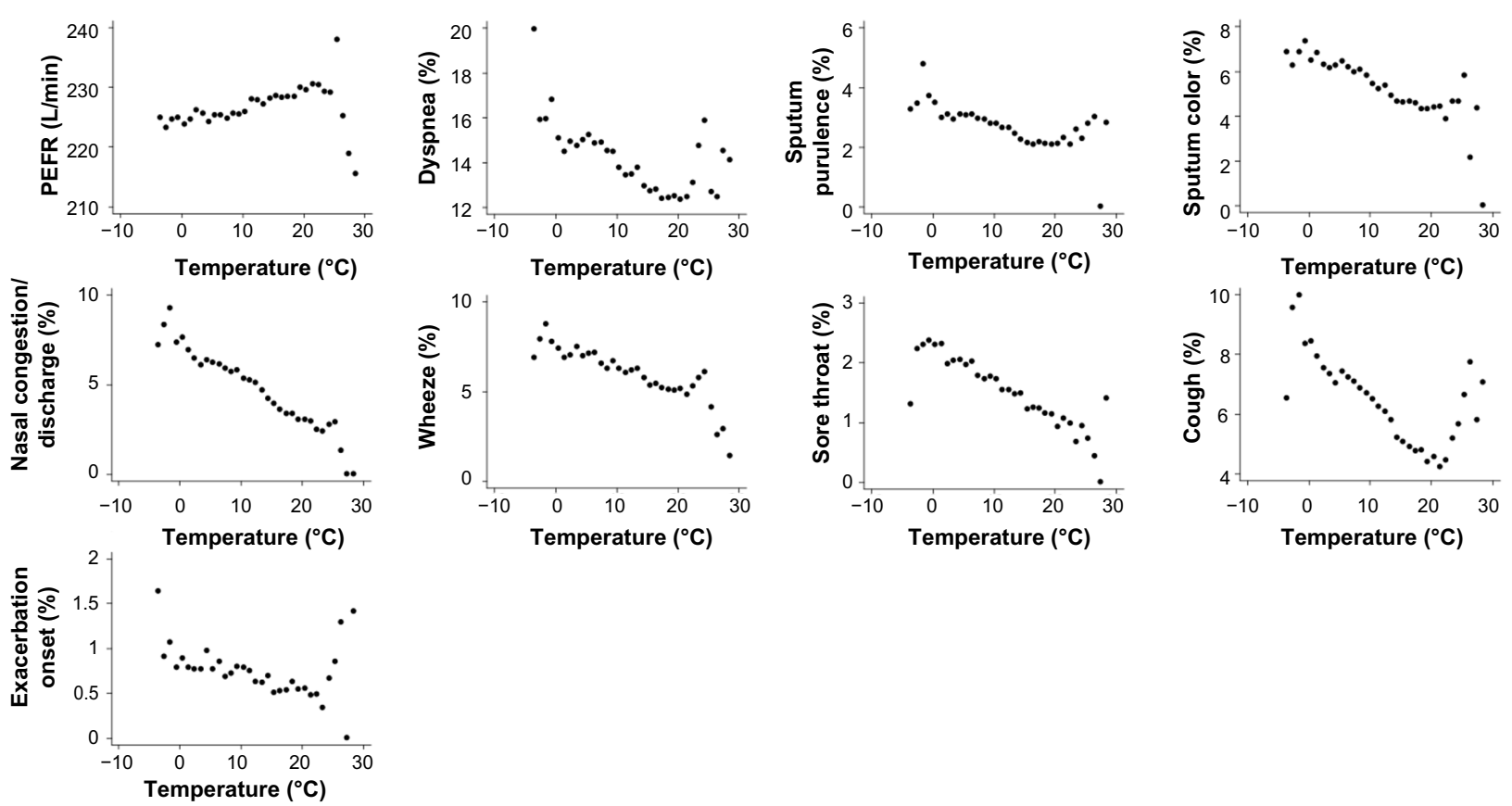

Figure 2 Diary-card data collected from the London COPD cohort between November 1995 and November 2012

Notes: Points are the percentage of patient-reporting activity, worsening of respiratory symptoms or onset of exacerbation on days within $I^{\circ} \mathrm{C}$, or average peak expiratory flow rate on those days.

Abbreviations: COPD, chronic obstructive pulmonary disease; PEFR, peak expiratory flow rate.

18 to April 30), which is equivalent to a $36.2 \%$ increase. ${ }^{15}$ This figure is not however comparable to the aforementioned studies, where winter was compared with summer. The study suggested that exacerbations are more likely over Christmas, when social events make cross-infection easier, but this spike over Christmas is not seen in other countries.

\section{Seasonality of patient-reported outcomes}

There is very little in the literature about the seasonality of patient-reported outcome measures collected directly from the patient, usually by questionnaire, concerning COPD exacerbations. Exacerbation frequency is an important determinant of health-related quality of life (St George's Respiratory Questionnaire [SGRQ] total scores) ${ }^{16}$ and these scores are higher in winter than spring or summer. ${ }^{17}$ Anxiety and depression scores are also related to exacerbation frequency, ${ }^{18}$ and higher in winter (11.6 [6.3] and 9.3 [2.7]) respectively, than summer (6.5 [4.3] and 6.0 [3.8]) $(P<0.001$ and $P<0.02$, respectively). ${ }^{19}$

The impact of exacerbations on patients also seems to vary between different periods of the year. Exacerbations took a median of 10 days (interquartile range [IQR] $6-19, \mathrm{n}=892)$ to recover in winter (November-February) compared to 9 days (IQR $5-16, \mathrm{n}=595 ; P=0.005$ ) in the summer (May-August). ${ }^{14}$ Patients spent less time outdoors during recovery from exacerbation in the winter (a fall of 0.5 hour/day [IQR -1.1 to 0 ] relative to just before the exacerbation started) compared to a fall of 0.26 hour/day (IQR -0.88 to 0.18$)$ in summer $(P=0.048)$.

\section{Seasonality of hospital admission}

Health services come under pressure in winter. ${ }^{20}$ This is due in part to increased hospital admissions for COPD exacerbations. The increase in admissions is observed across Europe, ${ }^{21}$ in Spain, ${ }^{22}$ Finland, ${ }^{23}$ Portugal,,${ }^{24}$ and the UK,,${ }^{25}$ and in the US, ${ }^{26}$ South Korea, ${ }^{27}$ and Hong Kong. ${ }^{28}$ The phenomenon, being consistent, is therefore predictable. Monthly admissions to hospital in Ontario, Canada over the previous year have a good correlation with the number of admissions in the following 12 months $\left(R^{2}=0.71\right)$, with all predictions falling inside $95 \%$ confidence intervals. ${ }^{29}$ In the UK, the Meteorological Office developed a scheme to alert patients and health care professionals to imminent cold weather and possible exacerbation of their disease. ${ }^{30}$ Though this was successful in predicting increased hospital admissions, a cost-benefit analysis suggested that patients needed to be targeted. In particular, those patients with frequent exacerbations (three or more in the previous 12 months) and those with one or two previous admissions could be approached. However, they account for only $8 \%$ and $22 \%$, respectively, of winter admissions, as $70 \%$ of patients admitted have no previous admission in the preceding 12 months. ${ }^{31}$ 
There are differing data over the role of socioeconomic factors concerning hospital admissions in winter. Jordan et $\mathrm{al}^{32}$ found no effect of socioeconomic deprivation (Townsend scores) or home-heating levels on hospital admissions, but did observe that being housebound and receiving two or more courses of oral corticosteroids in the previous year were significant predictive factors leading to admission. This study was relatively small, involving patients registered at 79 practices in central England, and relatively short, as it was conducted over only one winter (2003-2004). In a muchlarger study covering all COPD admissions in Scotland in the period 2001-2010, McAllister et $\mathrm{al}^{33}$ found a synergistic relationship between winter and deprivation, with a larger winter-summer difference of 39 compared to seven admissions for COPD per 10,000 person-years between the most and least deprived areas of Scotland.

The length of hospital stay appears also to vary with season. In a study of 153,401 hospital admissions between 1987 and 1998 across Finland, the length of stay was 12.3 days (standard deviation 62.3) in winter and 11.0 days (standard deviation 42.3) in summer $(P=0.001)$, and it was suggested that the light and warm northern summers serve to shorten hospital stays. ${ }^{34}$ Attendance at group pulmonary rehabilitation centers is also significantly lower in the winter, $64 \%$ compared to $74 \%$ during summer. ${ }^{35}$

\section{Winter pressures on primary care}

There have been very few investigations into the seasonality of primary care consultations. In a retrospective time-series analysis of primary care visits for respiratory disease in Ontario, Canada from January 1992 to December 2002, there was clear seasonality in COPD consultations, with more in winter, matching those in other respiratory diseases such as respiratory syncytial virus (RSV) infection and influenza-induced asthma. ${ }^{36}$

\section{Seasonality of mortality from COPD}

In England and Wales, about $15 \%$ of all deaths are from respiratory disease, and of these about $36 \%$ are due to COPD (International Classification of Diseases [ICD]-10 J40-J44). ${ }^{37}$ In a study of the UK population's vulnerability to winter mortality, seasonal variations in deaths from all causes can be explained almost entirely by a categorical variable for the month, average temperatures over the previous 13 days, and weekly influenza A counts from public health laboratories. ${ }^{38}$ This implied that these three factors alone determine excess winter mortality. Much of the excess winter mortality was in people with preexisting respiratory disease. This group experienced a winter:nonwinter ratio in mortality of 1.20 times greater than in people without a respiratory illness.

Deaths from COPD increase significantly during the cold weather experienced in winter, but this is generally mentioned as an adjunct to studies into the effects of atmospheric pollution. ${ }^{39,40}$ Few studies have specifically examined excess winter COPD mortality. Figure 3 shows clear seasonality in COPD deaths, which are consistently higher in winter and greater in older age-groups. An important difference between the effects of atmospheric pollutants and cold weather is that pollutants are associated with an immediate increase in COPD mortality, ${ }^{39}$ whereas temperature appears to have a delayed effect. Figure 4 shows that respiratory disease (ICD-9 460-519) peaks 12 days after a cold day. ${ }^{41}$ This difference in the delay-to-peak effect can be explained. Atmospheric pollutants cause bronchoconstriction and increased mucus production. This might be sufficient to tip the balance in already-seriously

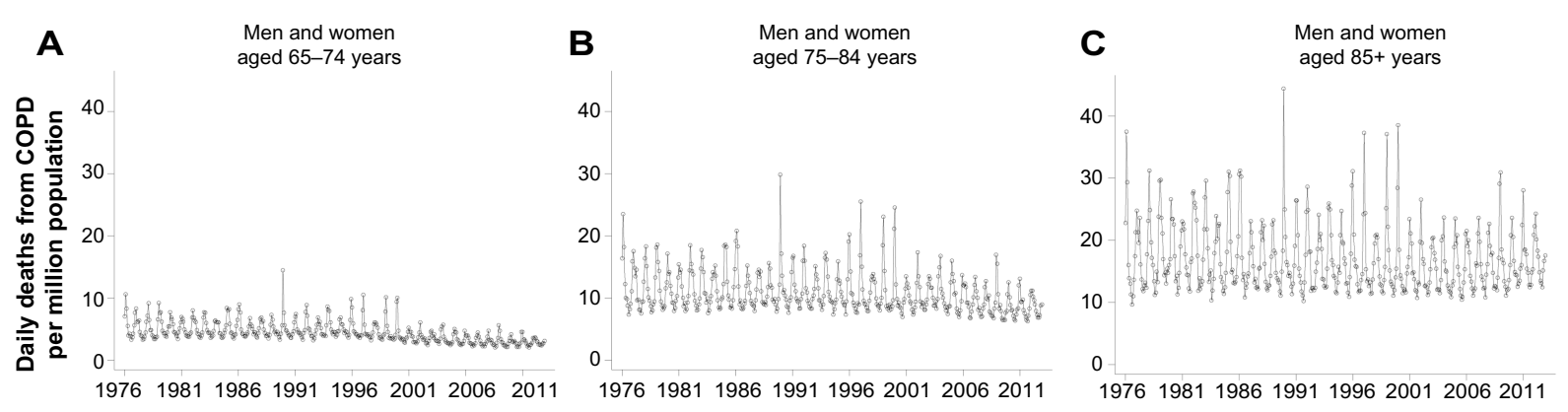

Figure 3 Seasonality of COPD mortality, by age.

Notes: Mean daily deaths per million population (mortality) for men and women aged 65-74, 75-84, and 85+ years for each month between 1976 and 2012 in England and Wales from COPD (coded with the ninth and tenth International Classification of Diseases [ICD] as ICD-9 490-492, 496 for years before 200I, and ICD-I0 J40-J44 thereafter) were extracted from death-registration data supplied by the Office of National Statistics (ONS). To be compatible with deaths before 1983 and after 1993 , daily deaths from COPD were divided by 0.940 to adjust for differences in mortality-coding instructions in the intervening years. Deaths classified using the ICD-I0 (200I-20I2) were divided by 0.966 to allow for differences between the ICD-9 and ICD-I0. Deaths per day per million population were obtained after dividing daily deaths by daily population estimates obtained by fitting a fifth-order polynomial to yearly estimates of the populations from the ONS from census data.

Abbreviation: COPD, chronic obstructive pulmonary disease. 


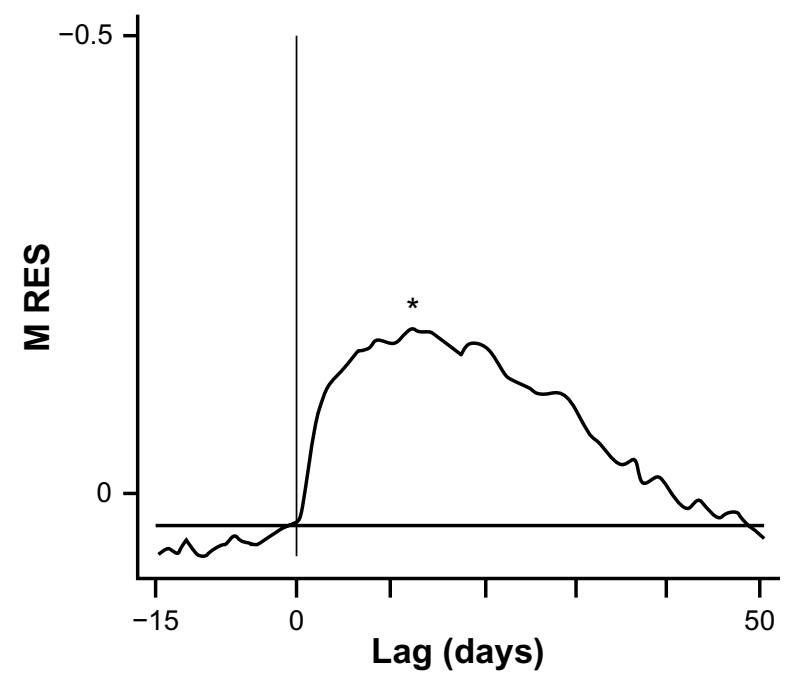

Figure 4 Time-series analysis showing the time courses of respiratory mortality following a cold day.

Notes: M RES describes the increase in mortality per $1{ }^{\circ} \mathrm{C}$ fall in temperature. The $y$-axis is the regression coefficients of mortality on temperature on days before and after day 0 . The horizontal line is the means of values at lag -30 to -16 days. *Peak value and significantly different from zero, $P<0.001$. Reproduced from J Epidemiol Community Health, Early increases in ischaemic heart disease mortality dissociated from and later changes associated with respiratory mortality after cold weather in south east England, Donaldson GC, Keatinge WR, 5I(6),643-648, copyright 1997, with permission from BMJ Publishing Group Ltd. ${ }^{40}$

Abbreviation: M RES, respiratory disease mortality.

ill individuals, whereas cold might increase the likelihood of infection, which once established takes time to progress and cause death.

\section{Indoor and outdoor cold exposure: warm housing}

There are epidemiologic data to suggest that increased respiratory mortality in winter is due both to indoor and outdoor cold exposure. The Eurowinter study examined mortality data for 1988-1992 in eight regions across Europe for people aged 50-59 and 65-74 years, and related their increases in mortality per $1^{\circ} \mathrm{C}$ fall in temperature to data on personal cold protection collected by a survey of 1,000 individuals of similar age and sex in each region. ${ }^{42}$ The study found greater cold-related respiratory mortality in warmer rather than colder regions of Europe. People living in warm regions paradoxically had colder living rooms and shivered more outdoors when the temperature was $7^{\circ} \mathrm{C} .{ }^{42}$ This was attributed to the people in cold regions protecting themselves better from the cold. Subsequent studies showed that it is possible for a population to avoid any increase in cold-related respiratory mortality over the temperatures range typically experienced in Western European countries. In the cities of Yekaterinburg (western Siberia) and Yakutsk (eastern Siberia), there was no increase in respiratory mortality as temperatures fell to $0^{\circ} \mathrm{C} .{ }^{43,44}$ The surveyed Russians generally had higher indoor temperatures and wore more and thicker clothing (a fur coat, hats, and gloves). Other adaptations were triple-glazed windows and buildings with double and sometimes triple sets of doors to the outside. These measures could be adopted elsewhere to keep houses warm and save on fuel.

These survey studies support the reasonable assumption that improvements in home heating can reduce excess winter deaths and hospital admissions. However, a systematic review of housing intervention ${ }^{45}$ found no improvement with regard to respiratory health in nine different European studies, although improvements in the respiratory health of children were observed in two New Zealand studies. ${ }^{46,47}$ Indeed, another study of elderly people living in fully heated housing and not directly charged for its cost experienced the same excess winter all-cause mortality as the surrounding elderly population. ${ }^{48,49}$ In COPD patients, a cross-sectional study of 148 individuals found only a weak associations $\left(R^{2}=0.14\right)$ between poorer scores in the symptom subcomponent of the SGRQ and fewer days with 9 hours of warmth $\left(>21^{\circ} \mathrm{C}\right)$ in the living room, independent of age, lung function, smoking, and outdoor temperatures. ${ }^{50}$ No improvements were seen in activity or impact scores or total SGRQ scores, or in the EuroQol Visual Analogue Scale, though the trends were in the direction that suggested that warmth improved respiratory health. One possibility is that cold outdoors is the most important determinant of respiratory mortality and morbidity, probably not through a direct effect on the body, but indirectly by prolonging the survival of viruses in the environment.

\section{Respiratory viruses and exacerbations}

An important cause of COPD exacerbations is airway infection by a respiratory virus. Table 1 shows that the detection rate of respiratory viruses at exacerbation varies from $22 \%,{ }^{51} 37 \%,{ }^{52} 39 \%,{ }^{53} 42 \%,{ }^{54}$ to $57 \% .{ }^{55}$ A fairly consistent finding is that the most common respiratory virus detected at COPD exacerbation is human rhinovirus. The results from Ko et $\mathrm{al}^{51}$ were detected in nasopharyngeal aspirates alone, while the other studies examined sputum and/or nasal lavage.

\section{Seasonality of respiratory viruses}

Figure 5 shows viral isolation counts from Public Health Agency laboratories for 1980-2008 for all ages and sexes, by week number. Influenza A, RSV and Mycoplasma pneumoniae occur mainly in the winter to early spring, 
Table I Prevalence of respiratory viruses at COPD exacerbation

\begin{tabular}{|c|c|c|c|c|c|}
\hline Respiratory virus & McManus et al $^{49}$ & Seemungal et $a^{50}$ & Beckham et al $^{51}$ & Rohde et $\mathbf{a l}^{52, \uparrow}$ & Ko et $\mathbf{a l}^{48}$ \\
\hline Exacerbations, $\mathrm{n}$ & 136 & 168 & 194 & 85 & 262 \\
\hline Virus-positive exacerbations (\%) & $50(36.8 \%)$ & $66(39.2 \%)$ & 81 (4I.8\%) & 48 (56.5\%) & $58(22.1 \%)$ \\
\hline Viruses detected, $\mathrm{n}$ & 56 & 77 & 88 & 59 & 56 \\
\hline Human rhinovirus* & $57 \%$ & $50 \%$ & $44 \%$ & $36 \%$ & $14 \%$ \\
\hline Influenza A & $5 \%$ & $8 \%$ & $16 \%$ & $25 \%$ & $32 \%$ \\
\hline Influenza B & 0 & $4 \%$ & $2 \%$ & $7 \%$ & $11 \%$ \\
\hline Corona & $2 \%$ & $9 \%$ & $18 \%$ & 0 & $21 \%$ \\
\hline Parainfluenza & $9 \%$ & $1 \%$ & $10 \%$ & $10 \%$ & $7 \%$ \\
\hline Adenovirus & $18 \%$ & $1 \%$ & $1 \%$ & 0 & $2 \%$ \\
\hline RSV & $6 \%$ & $25 \%$ & $8 \%$ & $22 \%$ & $11 \%$ \\
\hline Metapneumovirus & $4 \%$ & $1 \%$ & 0 & 0 & $2 \%$ \\
\hline
\end{tabular}

Notes: *Percentages for viral types are calculated as the percentage of viruses detected; totals may therefore exceed $100 \%$, as some samples had dual infection and/or rounding; ${ }^{\dagger}$ data combined for serology and polymerase chain reaction.

Abbreviations: COPD, chronic obstructive pulmonary disease; RSV, respiratory syncytial virus.

influenza B peaks in late spring, and parainfluenza in summer. Rhinoviruses, adenoviruses, and corona viruses occur throughout the year. Rhinovirus detection falls during the summer holidays, but rises around the time that the new academic year starts. Data from other countries will differ due to local social patterns and meteorological conditions, with the autumnal peak in the UK possibly not as pronounced as that observed in the US. ${ }^{56,57}$ One limitation of these data is that rates cannot be determined, as the number of people presenting to a physician with a respiratory infection is unknown. Furthermore, the decision to send a sample for investigation may be influenced
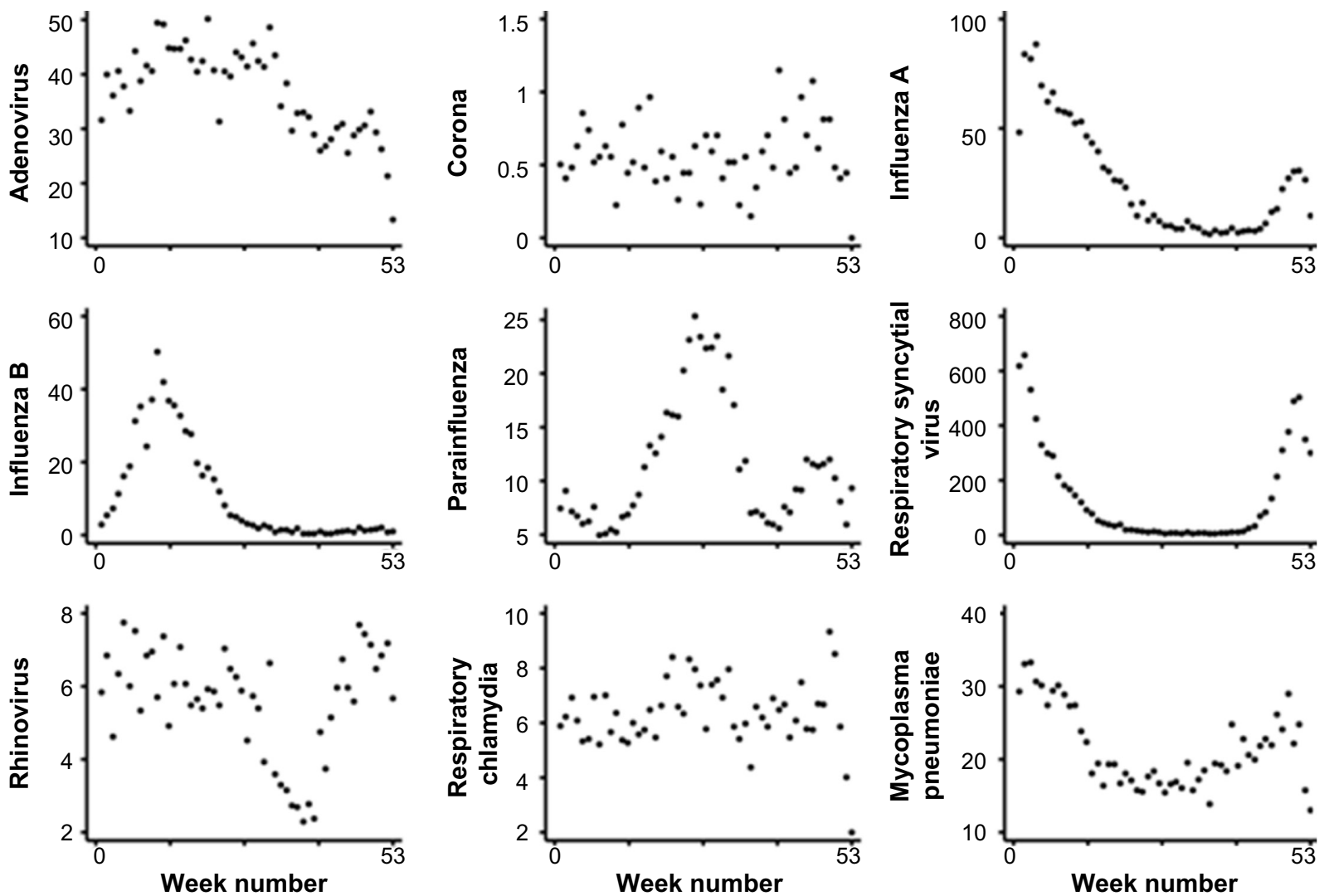

Figure $\mathbf{5}$ Weekly data on laboratory reports of respiratory virus isolation by the Health Protection Agency/Public Health England and National Health Service hospital laboratories in England and Wales.

Notes: Data points are the average for that week over years 1980-2013. The y-axes show the number of viruses isolated per week. Adapted from Respiratory infections: laboratory reports 2014 [homepage on the internet]. Public Health England; 20 I4 [updated September 5, 20I4]. Available from: https://www.gov.uk/government/publications/ respiratory-infections-laboratory-reports-20I4. Accessed September 24, 20I4. Contains public sector information licensed under the Open Government Licence v2.0. ${ }^{77}$ 
by concerns over the latest global epidemic or the age of the patient, as samples from young children tend to predominate. Therefore, comparisons from year to year are somewhat problematic.

The role of temperature in the development of respiratory infection is not clear. Some studies show that a cold environment can lead to the development of a cold. For example, in a study of 892 military recruits in Finland, ${ }^{58}$ a $1{ }^{\circ} \mathrm{C}$ fall in temperature increased the risk for an upper respiratory tract infection by $4.3 \%(P<0.0001)$, for the common cold by $2.1 \%(P=0.004)$, and for sore throat by $2.8 \%(P=0.019)$. The estimated risk of a lower respiratory tract infection was $2.1 \%$ per $1^{\circ} \mathrm{C}$ fall $(P=0.038)$. Similarly, in another study, 180 healthy medical students at Cardiff University who placed their feet in water at $10^{\circ} \mathrm{C}$ for 20 minutes reported 13 of 90 colds $4-5$ days later compared to 5 of 90 controls $(P=0.047) .{ }^{59}$ However, others have shown that cooling does not favor the development of a cold. At the Common Cold Research Unit, patients chilled at $60^{\circ} \mathrm{F}$ $\left(15.6^{\circ} \mathrm{C}\right)$ for 4 hours dressed solely in shorts and socks or for 2 hours in street clothes, overcoat, and hat and inoculated with infective secretions developed almost the same percentage of colds as unchilled subjects. ${ }^{60} \mathrm{~A}$ number of mechanisms have been proposed by which a cold environment might increase host susceptibility to infection. Breathing cold air might cool the nasal epithelium and inhibit respiratory defenses, such as mucociliary clearance, or reduce the phagocytic activity of leukocytes. ${ }^{61}$

Alternatively, a cold environment might favor the survival of viruses, and their longer life span facilitates transmission and cross-infection. Most respiratory viruses are transmitted with a coating of saliva or mucus that acts as a barrier to the environment, either in the form of aerosol droplets or through direct inoculation of noses or eyes..$^{56}$ Low temperatures $\left(7^{\circ} \mathrm{C}-8^{\circ} \mathrm{C}\right)$ are optimal for influenza survival. ${ }^{62} \mathrm{Tem}$ peratures above $60^{\circ} \mathrm{C}$ for more than 1 hour are considered sufficient to inactivate most viruses. An environment at a high relative humidity (70\%-90\%) also favors the survival of non-lipid-enveloped viruses, such as rhinoviruses and adenoviruses, although viruses with lipid envelopes (influenza, corona, RSV, parainfluenza) survive longer at a lower relative humidity $(20 \%-30 \%){ }^{62}$ More recent work suggests that absolute humidity has greater biological significance than relative humidity, though the precise biological mechanisms are unknown. ${ }^{63,64}$

Another possibility is that people crowd together indoors, thus facilitating cross-infection. Figure 6 shows that the proportion of patients with COPD going outdoors falls in cold weather. ${ }^{14}$ Although an attractive hypothesis, the small

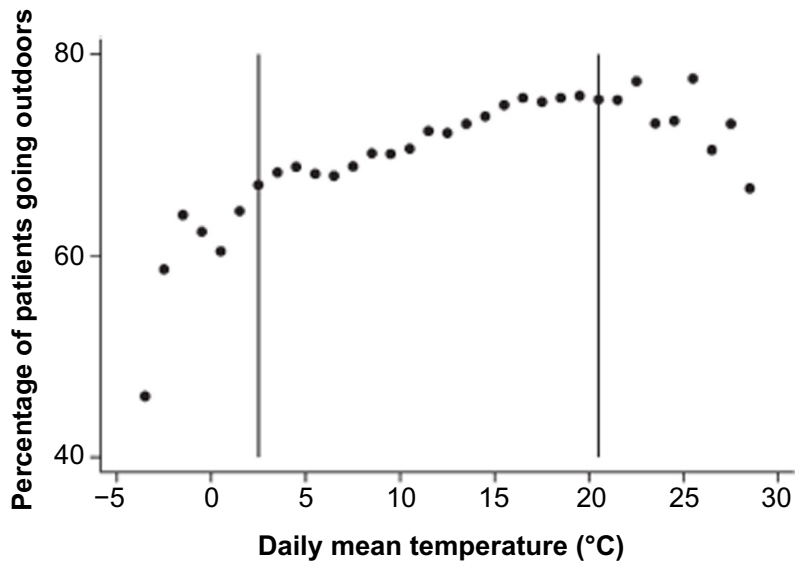

Figure 6 Percentage of patients going outside the home against the daily mean temperature throughout the year.

Notes: Points are at the center of each $1{ }^{\circ} \mathrm{C}$ interval; vertical lines are at $2.5^{\circ} \mathrm{C}$ and $20.5^{\circ} \mathrm{C}$. Reproduced with permission from the American College of Chest Physicians from Donaldson et al. ${ }^{14}$

differences in time spent indoors between summer and winter is possibly too small to explain the large seasonal differences in respiratory viral infections. Furthermore, many elderly people live alone, and the increased isolation from infected individuals would make it less likely that they would get an infection by cross-infection. There is evidence that COPD patients become more anxious when the media report on pandemics, as occurred in the $2009 \mathrm{H} 1 \mathrm{~N} 1$ pandemic in Melbourne, Australia. ${ }^{65}$

\section{Reducing exacerbation seasonality}

One way of reducing exacerbation seasonality would be to reduce the incidence of respiratory virus infection by immunization. Vaccines against human rhinovirus have not been successful, as there is little cross-protection between serotypes. Vaccination against influenza is widely available, and coverage has risen since 1980 from $15 \%$ to $65 \%$. The efficacy of influenza vaccination in the elderly has recently been challenged, ${ }^{66}$ questioned, ${ }^{67-69}$ and rebutted. ${ }^{70}$ However, any protection is extremely worthwhile, as the risk of death from respiratory and cardiovascular causes is high during an epidemic, with cardiovascular deaths being attributed to an increase in procoagulation factors, like fibrinogen, whose production in the liver is stimulated by the inflammatory marker interleukin $6 .^{71}$ Hand disinfection with ethanol does not appear to protect much against rhinoviral infection. ${ }^{72}$ Vitamin D supplementation has been proposed as a way of reducing seasonal exacerbations, as serum levels fall in winter due to lack of sunshine and deficiency is associated with increased infections, possibly by altering innate immunity. ${ }^{73}$ However, low 25-hydroxyvitamin D levels in 
COPD were not associated with frequent exacerbations, ${ }^{73,74}$ and therefore supplementation is probably unlikely to reduce seasonal exacerbations.

There is no published evidence that the seasonality of COPD exacerbations has fallen over recent years, but excess winter mortality from all causes and respiratory disease is decreasing. Data from 1977-1994 showed significant decline in increase in deaths per $1^{\circ} \mathrm{C}$ fall with and without allowance for influenza epidemics. ${ }^{75}$ This is thought to be due to adaptation of the population rather than higher temperatures through global climate change. ${ }^{76}$ Falls in all-cause winter mortality could be due to improved fuel efficiency and housing insulation, better diet, more affordable heating, and government coldweather payments, though the precise reasons are unknown.

\section{Conclusion}

The seasonality of COPD exacerbations is an important feature of COPD, and the mechanisms responsible are complex and interrelated. More research is always needed, but a fruitful area would be an investigation into the reasons for the decline in the UK over the last few decades in excess winter mortality from respiratory and other causes. If we knew why this was happening, then these adaptive strategies could be accelerated with greater confidence. The development of an effective human rhinovirus vaccine would be of major importance, irrespective of the seasonality, but difficult in view of the multiple types of rhinovirus circulating in the community. Further research is also needed concerning the best ways of persuading patients to help themselves. Improvements in compliance and adherence to medication, pulmonary rehabilitation, and smoking-cessation plans would be a cost-effective way of helping COPD patients. A specific area of research might be the use of seasonal treatment regimens where less anti-inflammatory medication is used in the summer when the patients have fewer respiratory symptoms and feel better, thus reducing side effects.

In summary, the seasonality of exacerbations imposes a considerable burden on COPD patients in terms of mortality and morbidity, and on health care systems responsible for patient care. This seasonality can be reduced. Further research and implementation of mitigation strategies would help patients with COPD.

\section{Disclosure}

The authors report no conflicts of interest in this work.

\section{References}

1. Aaron SD, Donaldson GC, Whitmore GA, Hurst JR, Ramsay T, Wedzicha JA. Time course and pattern of COPD exacerbation onset. Thorax. 2012;67(3):238-243.
2. Donaldson GC, Wedzicha JA. COPD exacerbations. 1: Epidemiology. Thorax. 2006;61(2):164-168.

3. Anthonisen NR, Manfreda J, Warren CP, Hershfield ES, Harding GK, Nelson NA. Antibiotic therapy in exacerbations of chronic obstructive pulmonary disease. Ann Intern Med. 1987;106(2):196-204.

4. National Clinical Guideline Centre. Chronic Obstructive Pulmonary Disease: Management of Chronic Obstructive Pulmonary Disease in Adults in Primary and Secondary Care. London: National Clinical Guideline Centre; 2010. http://guidance.nice.org.uk/CG101/Guidance/ pdf/English. Accessed August 4, 2014.

5. Wedzicha JA, Seemungal TA, MacCallum PK, et al. Acute exacerbations of chronic obstructive pulmonary disease are accompanied by elevations of plasma fibrinogen and serum IL-6 levels. Thromb Haemost. 2000;84(2):210-215.

6. Hurst J, Donaldson GC, Perera WR, et al. Use of plasma biomarkers at exacerbation of chronic obstructive pulmonary disease. Am J Respir Crit Care Med. 2006;174(8):867-874.

7. Bhowmik A, Seemungal TA, Sapsford RJ, Wedzicha JA. Relation of sputum inflammatory markers to symptoms and lung function changes in COPD exacerbations. Thorax. 2000;55(2):114-120.

8. Garcia-Gutierrez S, Quintana JM, Barrio I, et al. Application of appropriateness criteria for hospitalization in COPD exacerbation. Intern Emerg Med. 2013;8(4):349-357.

9. Calderon-Larranaga A, Carney L, Soljak M, et al. Association of population and primary healthcare factors with hospital admission rates for chronic obstructive pulmonary disease in England: national cross-sectional study. Thorax. 2011;66(3):191-196.

10. Organisation for Economic Co-operation and Development. Health at a Glance 2011: OECD Indicators. Paris: OECD; 2011. Available from: http:// dx.doi.org/10.1787/health_glance-2011-en. Accessed August 4, 2014.

11. Jenkins CR, Celli B, Anderson JA, et al. Seasonality and determinants of moderate and severe COPD exacerbations in the TORCH study. Eur Respir J. 2012;39(1):38-45.

12. Rabe KF, Fabbri LM, Vogelmeier C, et al. Seasonal distribution of COPD exacerbations in the Prevention of Exacerbations with Tiotropium in COPD trial. Chest. 2013;143(3):711-719.

13. Donaldson GC, Seemungal T, Jeffries DJ, Wedzicha JA. Effect of temperature on lung function and symptoms in chronic obstructive pulmonary disease. Eur Respir J. 1999;13(4):844-849.

14. Donaldson GC, Goldring JJ, Wedzicha JA. Influence of season on exacerbation characteristics in patients with COPD. Chest. 2012;141(1): 94-100.

15. Johnston NW, McIvor A, Lambert K, et al. The Christmas season as a risk factor for chronic obstructive pulmonary disease exacerbations. Can Respir J. 2010;17(6):275-281.

16. Seemungal TA, Donaldson GC, Paul EA, Bestall JC, Jeffries DJ, Wedzicha JA. Effect of exacerbation on quality of life in patients with chronic obstructive pulmonary disease. Am J Respir Crit Care Med. 1998;157(5 Pt 1):1418-1422.

17. Miravitlles M, Ferrer M, Pont A, et al. Effect of exacerbations on quality of life in patients with chronic obstructive pulmonary disease: a 2 year follow up study. Thorax. 2004;59(5):387-395.

18. Quint JK, Baghai-Ravary R, Donaldson GC, Wedzicha JA. Relationship between depression and exacerbations in COPD. Eur Respir J. 2008;32(1):53-60.

19. Singh SJ, Sewell L, Williams JE, Morgan MD. Seasonal variations in exercise tolerance, activity and quality of life in patients with chronic obstructive pulmonary disease (COPD). Poster presented at: 15th Annual Congress of the European Respiratory Society; September 17-21, 2005; Copenhagen, Denmark.

20. Public Health England. Cold Weather Plan for England 2013: Protecting Health and Reducing Harm from Cold Weather. London: Public Health England; 2013. Available from: https://www.gov.uk/ government/uploads/system/uploads/attachment_data/file/252838/ Cold_Weather_Plan_2013_final.pdf. Accessed August 4, 2014.

21. Anderson HR, Spix C, Medina S, et al. Air pollution and daily admissions for chronic obstructive pulmonary disease in 6 European cities: results from the APHEA project. Eur Respir J. 1997;10(5): 1064-1071. 
22. Ballester F, Pérez-Hoyos S, Rivera ML, et al. [The patterns of use and factors associated with the patient admission of hospital emergencies for asthma and chronic obstructive pulmonary disease]. Arch Bronconeumol. 1999;35(1):20-26. Spanish.

23. Vilkman S, Keistinen T, Tuuponen T, Kivelä SL. Seasonal variation in hospital admissions for chronic obstructive pulmonary disease in Finland. Arctic Med Res. 1996;55(4):182-186.

24. Monteiro A, Carvalho V, Góis J, Sousa C. Use of "Cold Spell” indices to quantify excess chronic obstructive pulmonary disease (COPD) morbidity during winter (November to March 2000-2007): case study in Porto. Int J Biometeorol. 2013;57(6):857-870.

25. Brims FJ, Asiimwe A, Andrews NP, et al. Weekend admission and mortality from acute exacerbations of chronic obstructive pulmonary disease in winter. Clin Med. 2011;11(4):334-339.

26. Mapel DW, Dedrick D, Davis K. Trends and cardiovascular comorbidities of COPD patients in the Veterans Administration Medical System, 1991-1999. COPD. 2005;2(1):35-41

27. Lim YH, Hong YC, Kim H. Effects of diurnal temperature range on cardiovascular and respiratory hospital admissions in Korea. Sci Total Environ. 2012;417-418:55-60.

28. Ko FW, Tam W, Wong TW, et al. Temporal relationship between air pollutants and hospital admissions for chronic obstructive pulmonary disease in Hong Kong. Thorax. 2007;62(9):780-785.

29. Upshur RE, Moineddin R, Crighton E, Kiefer L, Mamdani M. Simplicity within complexity: seasonality and predictability of hospital admissions in the province of Ontario 1988-2001, a population-based analysis. BMC Health Serv Res. 2005;5(1):13.

30. Marno P, Chalder M, Laing-Morton T, Levy M, Sachon P, Halpin D. Can a health forecasting service offer COPD patients a novel way to manage their condition? J Health Serv Res Policy. 2010;15(3): 150-155.

31. Bryden C, Bird W, Titley HA, Halpin DM, Levy ML. Stratification of COPD patients by previous admission for targeting of preventative care. Respir Med. 2009;103(4):558-565.

32. Jordan RE, Hawker JI, Ayres JG, et al. Effect of social factors on winter hospital admission for respiratory disease: a case-control study of older people in the UK. Br J Gen Pract. 2008;58(551):400-402.

33. McAllister DA, Morling JR, Fischbacher CM, MacNee W, Wild SH. Socioeconomic deprivation increases the effect of winter on admissions to hospital with COPD: retrospective analysis of 10 years of national hospitalisation data. Prim Care Respir J. 2013;22(3): 296-299.

34. Kinnunen T, Säynäjäkangs O, Tuuponen T, Keistinen T. Regional and seasonal variation in the length of hospital stay for chronic obstructive pulmonary disease in Finland. Int J Circumpolar Health. 2002;61(2):131-135.

35. Walker GE, Lee C, Elkin SL. Seasonality and attendance at a pulmonary rehabilitation programme. Thorax. 2011;66(7):634-635.

36. Moineddin R, Nie JX, Domb G, Leong AM, Upshur RE. Seasonality of primary care utilization for respiratory diseases in Ontario: a timeseries analysis. BMC Health Serv Res. 2008;8:160.

37. Mannino DM, Homa DM, Akinbami LJ, Ford ES, Redd SC. Chronic obstructive pulmonary disease surveillance--United States, 1971-2000. Respir Care. 2002;47(10):1184-1199.

38. Wilkinson P, Pattenden S, Armstrong B, et al. Vulnerability to winter mortality in elderly people in Britain: population based study. BMJ. 2004;329(7467):647.

39. Wordley J, Walters S, Ayres JG. Short term variations in hospital admissions and mortality and particulate air pollution. Occup Environ Med. 1997;54(2):108-116.

40. Kelsall JE, Samet JM, Zeger SL, Xu J. Air pollution and mortality in Philadelphia, 1974-1988. Am J Epidemiol. 1997;146(9):750-762.

41. Donaldson GC, Keatinge WR. Early increases in ischaemic heart disease mortality dissociated from and later changes associated with respiratory mortality after cold weather in south east England. J Epidemiol Community Health. 1997;51(6):643-648.

42. Group TE. Cold exposure and winter mortality from ischaemic heart disease, cerebrovascular disease, respiratory disease, and all causes in warm and cold regions of Europe. The Eurowinter Group. Lancet. 1997;349(9062):1341-1346.
43. Donaldson GC, Tchernjavskii VE, Ermakov SP, Bucher K, Keatinge WR. Winter mortality and cold stress in Yekaterinburg, Russia: interview survey. BMJ. 1998;316(7130):514-518.

44. Donaldson GC, Ermakov SP, Komarov YM, McDonald CP, Keatinge WR. Cold related mortalities and protection against cold in Yakutsk, eastern Siberia: observation and interview study. BMJ. 1998;317(7164):978-982.

45. Thomson H, Petticrew M, Morrison D. Health effects of housing improvement: systematic review of intervention studies. BMJ. 2001;323(7306):187-190.

46. Howden-Chapman P, Pierse N, Nicholls S, et al. Effects of improved home heating on asthma in community dwelling children: randomised controlled trial. BMJ. 2008;337:a1411.

47. Howden-Chapman P, Matheson A, Crane J, et al. Effect of insulating existing houses on health inequality: cluster randomised study in the community. BMJ. 2007;334(7591):460.

48. Keatinge W, Donaldson G. Winter deaths: warm housing is not enough. BMJ. 2001;323(7305):166-167.

49. Keatinge WR. Seasonal mortality among elderly people with unrestricted home heating. Br Med J (Clin Res Ed). 1986;293(6549):732-733.

50. Osman LM, Ayres JG, Garden C, Reglitz K, Lyon J, Douglas JG. Home warmth and health status of COPD patients. Eur J Public Health. 2008;18(4):399-405.

51. Ko FW, Ip M, Chan PK, et al. Viral etiology of acute exacerbations of COPD in Hong Kong. Chest. 2007;132(3):900-908.

52. McManus TE, Marley AM, Baxter N, et al. Respiratory viral infection in exacerbations of COPD. Respir Med. 2008;102(11):1575-1580.

53. Seemungal T, Harper-Owen R, Bhowmik A, et al. Respiratory viruses, symptoms, and inflammatory markers in acute exacerbations and stable chronic obstructive pulmonary disease. Am J Respir Crit care Med. 2001;164(9):1618-1623.

54. Beckham JD, Cadena A, Lin J, et al. Respiratory viral infections in patients with chronic, obstructive pulmonary disease. J Infect. 2005;50(4):322-330.

55. Rohde G, Wiethege A, Borg I, et al. Respiratory viruses in exacerbations of chronic obstructive pulmonary disease requiring hospitalisation: a case-control study. Thorax. 2003;58(1):37-42.

56. Monto AS. Epidemiology of viral respiratory infections. Am J Med. 2002;112 Suppl 6A:4S-12S

57. Monto AS. The seasonality of rhinovirus infections and its implications for clinical recognition. Clin Ther. 2002;24(12):1987-1997.

58. Mäkinen TM, Juvonen R, Jokelainen J, et al. Cold temperature and low humidity are associated with increased occurrence of respiratory tract infections. Respir Med. 2009;103(3):456-462.

59. Johnson C, Eccles R. Acute cooling of the feet and the onset of common cold symptoms. Fam Pract. 2005;22(6):608-613.

60. Dowling HF, Jackson GG, Spiesman IG, Inouye T. Transmission of the common cold to volunteers under controlled conditions. III. The effect of chilling of the subjects upon susceptibility. Am J Hyg. 1958;68(1):59-65.

61. Eccles R. An explanation for the seasonality of acute upper respiratory tract viral infections. Acta Otolaryngol. 2002;122(2):183-191.

62. Tang JW. The effect of environmental parameters on the survival of airborne infectious agents. J R Soc Interface. 2009;6 Suppl 6: S737-S746.

63. Yang W, Elankumaran S, Marr LC. Relationship between humidity and influenza a viability in droplets and implications for influenza's seasonality. PloS One. 2012;7(10):e46789.

64. Shaman J, Kohn M. Absolute humidity modulates influenza survival, transmission, and seasonality. Proc Natl Acad Sci USA 2009;106(9):3243-3248.

65. Hutchinson AF, Thompson MA, Clark L, Irving LB. Communicating information regarding human H1N1-09 virus to high-risk consumers: knowledge and understanding of COPD patients in Melbourne, Australia. Collegian. 2010;17(4):199-205.

66. Simonsen L, Taylor RJ, Viboud C, Miller MA, Jackson LA. Mortality benefits of influenza vaccination in elderly people: an ongoing controversy. Lancet Infect Dis. 2007;7(10):658-666. 
67. Thijs C, Beyer WE, Govaert PM, Sprenger MJ, Dinant GJ, Knottnerus A. Mortality benefits of influenza vaccination in elderly people. Lancet Infect Dis. 2008;8(8):460-461; author reply 463-465.

68. Kelly H, Newall AT. Mortality benefits of influenza vaccination in elderly people. Lancet Infect Dis. 2008;8(8):462-463; author reply 463-465.

69. Voordouw BC, Sturkenboom MC, Dieleman JP, Stricker BH. Mortality benefits of influenza vaccination in elderly people. Lancet Infect Dis. 2008;8(8):461-462; author reply 463-465.

70. Simonsen L, Taylor RJ, Viboud C, Miller MA, Jackson LA. Mortality benefits of influenza vaccination in elderly people - authors' reply. Lancet Infect Dis. 2008;8(8):463-465.

71. Wedzicha JA, Seemungal TA, MacCallum PK, et al. Acute exacerbations of chronic obstructive pulmonary disease are accompanied by elevations of plasma fibrinogen and serum IL-6 levels. Thromb Haemost. 2000;84(2):210-215.

72. Turner RB, Fuls JL, Rodgers ND, Goldfarb HB, Lockhart LK, Aust LB. A randomized trial of the efficacy of hand disinfection for prevention of rhinovirus infection. Clin Infect Dis. 2012;54(10):1422-1426.
73. Quint JK, Donaldson GC, Wassef N, Hurst JR, Thomas M, Wedzicha JA. 25-hydroxyvitamin D deficiency, exacerbation frequency and human rhinovirus exacerbations in chronic obstructive pulmonary disease. BMC Pulm Med. 2012;12:28.

74. Puhan MA, Siebeling L, Frei A, Zoller M, Bischoff-Ferrari H, ter Riet G. NO association of 25-hydroxyvitamin D with exacerbations in primary care patients with COPD. Chest. 2014;145(1):37-43.

75. Donaldson GC, Keatinge WR. Mortality related to cold weather in elderly people in southeast England, 1979-1994. BMJ. 1997;315(7115): 1055-1056.

76. Christidis N, Donaldson G, Stott PA. Causes for the recent changes in cold- and heat-related mortality in England and Wales. Clim Change. 2010;102(3-4):539-553.

77. Respiratory infections: laboratory reports 2014 [homepage on the internet]. Public Health England; 2014 [updated September 5, 2014]. Available from: https://www.gov.uk/government/publications/ respiratory-infections-laboratory-reports-2014. Accessed September 24, 2014. Contains public sector information licensed under the Open Government Licence v2.0.

\section{Publish your work in this journal}

The International Journal of COPD is an international, peer-reviewed journal of therapeutics and pharmacology focusing on concise rapid reporting of clinical studies and reviews in COPD. Special focus is given to the pathophysiological processes underlying the disease, intervention programs, patient focused education, and self management protocols.

\section{Dovepress}

This journal is indexed on PubMed Central, MedLine and CAS. The manuscript management system is completely online and includes a very quick and fair peer-review system, which is all easy to use. Visit http://www.dovepress.com/testimonials.php to read real quotes from published authors. 